\title{
PLANTÃO PSICOLÓGICO: UM ENCONTRO COM O OUTRO NA URGÊNCIA
}

\author{
Andréa Marques Leão Doescher \\ Wilma Magaldi Henriques"
}

\begin{abstract}
RESUMO. Este artigo tem por objetivo refletir sobre o encontro entre o terapeuta e a pessoa que busca pelo Plantão Psicológico, bem como o que pode ser feito neste tempo de urgência. Para isto, foi feita uma síntese sobre o que é um Plantão Psicológico, a pessoa que procurar por este serviço e as características necessárias a quem deseja ser um plantonista. Será exemplificado por meio de alguns relatos de casos atendidos numa Clínica Escola de Psicologia de uma Universidade do Alto Tietê, Estado de São Paulo, o que pode ser feito neste tempo que urge.
\end{abstract}

Palavras-chave: Plantão psicológico; urgência; possibilidades.

\section{PSYCHOLOGICAL EMERGENCY ATTENDANCE}

\begin{abstract}
This study reflects on the encounter between the therapist and the person seeking the Psychological emergency attendance and what can be done at this time of urgency. To this end, we present a synthesis about the psychological emergency attendance service, the person seeking this service and the characteristics required to work as a psychologist on duty. Moreover, it is presented what can be done at this urgent time through some reports of cases treated in a school psychology clinic from a university in the Alto do Tietê, São Paulo State.
\end{abstract}

Key words: Psychological emergency; urgency; possibilities.

\section{PSICOLÓGICA DE URGENCIA: UN ENCUENTRO CON OTROS EN EMERGENCIA}

RESUMEN. En artículo busca reflexionar sobre el encuentro que se produce entre el terapeuta y la persona que busca por la Guardia Psicológica, así como lo que se puede hacer en este tiempo de urgencia. Para ello, se presenta una síntesis de lo que es una Guardia Psicológica, la persona que busca por este servicio y las características necesarias para quien desee actuar en este contexto. Además, a través de algunos relatos de casos atendidos en una Clínica Enseñanza de Psicología de una Universidad del Alto Tietê, estado de São Paulo, se ejemplifica lo que se puede hacer en este momento de urgencia.

Palabras-clave: Guardia Psicológica; urgencia; posibilidades.

Psicóloga, mestre em Computação Aplicada, área de Neurociência, pelo Instituto Nacional de Pesquisas Espaciais (2000).

\# Doutora em Psicologia Escolar e do Desenvolvimento Humano pela Universidade de São Paulo (2005); professora supervisora de Estágio no curso de Psicologia da Universidade de Mogi das Cruzes. 
Este artigo tem por objetivo refletir sobre o encontro que se dá entre o terapeuta e a pessoa que busca pelo Plantão Psicológico. Para isto, fizemos uma breve síntese sobre o que é um Plantão Psicológico, quem procura por este serviço e o que pode ser feito neste momento da urgência.

O Plantão Psicológico (PP) é um tipo de intervenção psicológica que acolhe a pessoa no exato momento de sua urgência, ajudando-a a lidar melhor com seus recursos e limites. Desta forma, o objetivo de um PP é prestar atendimento urgencial à demanda, acompanhando a pessoa em busca do sentido de existência por meio da compreensão de seu sofrimento, sem, contudo, garantir alívio ou um viver baseado na experiência de prazer imediato e presente (Chaves \& Henriques, 2008).

De acordo com Cautella Júnior (2009), ao propiciar à pessoa uma visão mais clara e abrangente de si e suas perspectivas frente às suas questões, promovendo o autoquestionamento, o posicionando frente aos seus conflitos e o poder de fazer escolhas, o psicólogo está, desta forma, promovendo saúde e possibilitando um resgate da própria identidade. Neste contexto, o tempo que urge é também o das possibilidades, do encontro com outro e consigo mesmo.

Com relação ao psicólogo plantonista, o referido autor afirma que este deve estar disposto ao nãoplanejado, à possibilidade do encontro ser único e, tentar responder à demanda daquele que procura por este serviço naquele momento específico.

As palavras de Clarice Lispector (1988), na obra "A Descoberta do Mundo", em que diz para se render e mergulhar no desconhecido, ilustram de forma poética a postura que deve ter um psicólogo no contexto do PP. Em suma, o render-se, soltar as amarras dos preconceitos, do desinteresse, da incredulidade no outro faz com que o encontro possibilite aceitação e acolhimento.

No tempo da urgência, daquele que vai à procura do socorro e alívio, o plantonista ao estar disposto a se "abandonar", a se entregar à escuta do outro neste momento, é o que possibilitará ser afetado e ajudar, ou em outras palavras, cuidar de quem procura por este serviço.

Boff (1999) ressalta que o cuidado é mais que um ato, é uma atitude de ocupação, preocupação, de responsabilização e de envolvimento afetivo com uma pessoa. Ainda de acordo com o mesmo autor, o cuidado como modo-de-ser perpassa toda existência humana e possui ressonâncias como: o amor, a justa medida, a ternura, a carícia, a cordialidade, a convivialidade e a compaixão que garantem a humanidade dos seres humanos.
Nesse sentido, no contexto do PP, o encontro com aquele que na sua urgência nos procura é também um momento do cuidar, isto é, de se ocupar com a pessoa que nos procura - dirigirmos nossa escuta e atenção a ela; de nos "pré-ocuparmos"1 com esta, tendo legítimo interesse pelo que nos traz; de nos envolvermos afetivamente de modo empático, e estas características possibilitam que este momento, que pode ser único, possa ecoar, ter significações à pessoa que o procurou, bem como para aquele que a atende. Portanto, o cuidado, o zelo, a atenção, a "pré-ocupação" com o outro são condições fundamentais para o seu acontecer.

\section{QUEM PROCURA PELO PLANTÃO PSICOLÓGICO?}

Além da urgência, que configura o PP, quem e por que procura por este serviço? Sapienza (2007) diz que a pessoa que procura pelos serviços da Psicologia é aquele que "se aflige pelas escolhas que tem que fazer; sofre por suas perdas; tem que se haver com seus amores e desamores; se angustia diante da finitude e não tem como não se preocupar com sua vida" (p. 48). Enfim, é um ser humano ou, usando as palavras de Heidegger (2001), é um ser-aí, um ser-no-mundo, um não-ser que pode-ser, um caminhante de um caminho não-linear, o qual é feito e refeito a cada suspiro. Ser um "ser-aî" implica em captar e responder àquilo que se apresenta, tendo liberdade para responder como se deseja - sendo que a recusa em responder ao que é solicitado, por si só já é uma resposta -, e este modo de ser constitui o modo de ser humano (Pompéia \& Sapienza, 2004). Tristeza, sofrimento, ansiedade, angústias, desespero, entre outros, perpassam o viver humano e são desta forma respostas ao que se apresenta. Em algumas circunstâncias e momentos da vida, é difícil lidar com o que se apresenta e com o que isto nos mobiliza, o que faz com que o ser-aí recorra à ajuda, sendo o PP uma das muitas formas possíveis para o acolhimento desse sofrimento.

Este ser que se aflige, sente dores, angústias etc., por motivos mais diversos possíveis, é um ser que sofre. Segundo Tillich (1976), o ser humano é capaz de sofrer, mas não precisa deixar o sofrimento dominar o núcleo de seu ser racional, podendo manterse acima dele. No PP, o sofrimento, em muitos casos,

\footnotetext{
Henriques (2005) afirma que na preocupação podem-se destacar diferentes possibilidades: a preocupação substitutiva ou substituição dominadora quando se substitui o cuidado com o outro e ocupa esse outro e a preocupação de anteposição ou libertadora, a presença enquanto cuidado: mantém-se na cura, volta-se para a existência do outro e não dela se ocupa, portanto, cuida.
} 
não apenas tem dominado este ser-no-mundo, como anestesiado e ditado a forma deste entrar, ou não, em contato com seus sentimentos, com o seu próprio ser.

Calligaris (2008) observa que a vida é como uma breve passagem por um circuito de montanhas-russas e, vivenciar tal experiência anestesiado, sem gritos, pavor e risos, é como jogar o dinheiro do bilhete fora. Favorecer com que a pessoa que procura pelo PP possa entrar em contato com seus sentimentos, com o seu ser, é propiciar que este bilhete da vida não seja jogado fora.

Além das dores, angústias, dúvidas etc., a pessoa traz consigo a singularização dos seus ancestrais, da comunidade a qual pertence e vive, bem como as questões do destino humano, as quais são universais (Safra, 2004). Sendo assim, o encontro no PP não se dá entre duas pessoas, mas entre várias - plantonista, a pessoa que recorre a este serviço, aos pais desta etc. As questões trazidas são, então, as peculiares e próprias da pessoa, como também comuns a uma comunidade, aos seres mortais de forma geral.

O ser mortal, condição universal a todo ser humano, implica em ter que lidar com os limites impostos pela condição de mortal, de não poder fazer tudo, de não poder ter e ser tudo, remetendo este homem a fazer escolhas, a se responsabilizar por estas e arcar com as perdas (mortes) das outras possibilidades. Neste sentido, este ser-aí se angustia pelas suas possibilidades de ser neste mundo. A angústia, desta forma, é inerente da condição humana, mas também ela arremessa este homem para seu próprio poderser-no-mundo e revela o ser-aí como ser possível.

Entretanto, no mundo onde os ditames sociais são baseados e fundamentados na pressa, não cabe à angústia, o entrar em contato com ela, como também não cabe a dor, o sofrimento, as desilusões de um sonho não-concretizado, o vazio. $\mathrm{Na}$ sociedade do "fast food", a angústia tem que ser banida, a dor negada, o sofrimento afastado, os sonhos enterrados. E muitas pessoas que recorrem ao PP procuram assim, por uma forma rápida e fácil de aliviar e afastar a dor, as desilusões, as frustrações como se estas não fizessem parte da existência humana. O PP pode ser um espaço no qual estes sentimentos podem ser experienciados, sentidos, significados e ressignificados, integrados na história de vida como algo comum do viver humano.

\section{PLANTONISTA PSICOLÓGICO: QUAIS SÃO AS CARACTERÍSTICAS NECESSÁRIAS PARA O ENCONTRO COM O OUTRO NUM TEMPO QUE URGE?}

Calligaris (2008), refletindo sobre as características necessárias a quem deseja ser terapeuta, aponta: o contemplar com carinho e sem julgar a variedade de condutas humanas; ser humilde na aceitação das condições impostas por seus pacientes; o gosto pela palavra; paixão pela literatura; curiosidade para com o mundo, a vida e a cultura além das quatro paredes do consultório; terapia pessoal, e não deslumbrar, se tornar um notável, admirado e amado pelo mundo. Em se tratando de um plantonista, tais características não são diferentes e se aplicam a este.

Soma-se a estas características, o saber e querer ouvir de forma paciente e interessada, bem como o falar de forma compreensível e com amabilidade ao que procura pelo PP. Safra (2004) diz que, na situação clínica, nos posicionamos frente às grandes questões existenciais peculiares ao destino humano, sendo importante que a verbalização do psicólogo esteja aparentada com o idioma pessoal do paciente, com a maneira como ele concebe sua existência e com o modo de formulação de suas questões.

Além disso, é fundamental estar-se posicionado, conforme afirma Safra (2004), no não-saber, de forma que a singularidade daquele que procura pelo PP possa aparecer. $\mathrm{Na}$ atualidade, é comum a pessoa, de antemão, estar 'classificada em categorias conceituais, estruturas ou quadro psicopatológicos'. Tais classificações, num tempo de urgência, contaminam a escuta do plantonista e dificulta, ou impede, com que a singularidade da pessoa que recorre ao PP brote e, que assim, aquilo que a traz para este espaço se mostre, se revele. Desta forma, além do não-saber, é importante que o plantonista não seja tomado pela ânsia de ter que fazer algo, e isto de forma rápida. Na pressa de se ter que fazer algo, escapa dos sentidos e da compreensão o ser-aí que se coloca ante a um desconhecido em busca de algo que, em muitos casos, nem ele sabe o que é, que não consegue nomear, mas que o incomoda de forma significativa a ponto de o remeter a este movimento.

Não apenas as categorizações psicológicas contaminam a escuta do plantonista, como também o permitir com que os sentimentos pessoais se misturem com o da pessoa do encontro psicológico. Sobre isso, Sapienza (2007) afirma que:

\footnotetext{
Deixar de sentir, ignorar o quanto essas desgraças súbitas mexem comigo, isso não posso... Eu só não posso me afundar na dor que é dela, que eu compartilho porque, sendo gente, dói também em mim ver gente sofrendo. Mas é ela quem tem que se apropriar da dor pelo que ela perdeu. Foi ela quem perdeu. Só assim vou poder ajudá-la a se reencontrar, quem sabe (p. 62).
}

Em linhas gerais, são características imprescindíveis para o plantonista do PP: uma abordagem autêntica, a compreensão empática, a 
escuta atenta e acolhedora, assim como, a aceitação incondicional ao modo como o outro se revela, afinal o plantonista é o profissional do encontro... do encontro com a diferença.

\section{O QUE PODE SER FEITO NESTE TEMPO DA URGÊNCIA?}

Exemplificaremos aqui o que pode ser feito neste tempo que urge com alguns relatos de casos atendidos no PP de uma Clínica Escola de Psicologia de uma Universidade do Alto Tietê, Estado de São Paulo. Ressalte-se que os nomes estão abreviados, de forma a salvaguardar o anonimato das pessoas que procuraram por este serviço.

F., 26 anos, solteiro, estudante de Direito e funcionário administrativo do setor privado, conta que sua mãe, com quem morava e tinha um bom relacionamento, faleceu em seus braços em novembro de 2009. Desde então, ele não consegue sair de casa exceto para ir ao trabalho, ficando "trancado" em seu quarto. Além disso, F. se sente desrespeitado pelos irmãos (8 no total) que decidem, sem o consultar, que um deles irá morar com sua esposa e três filhos, na casa em que F. reside. Além do estranhamento à sua nova situação, F. sente-se só e com medo de que "isto" [sic] afete sua vida profissional. Ao ser perguntado como "isto" poderia afetar sua vida, ele responde que tem medo de chorar no serviço. "E você tem chorado em algum lugar?" [sic], e F. responde que não balançando a cabeça, chorando de forma intensa por alguns minutos.

Neste atendimento, além do espaço para falar de seus sentimentos, é apontado para F. que ele é humano, pode sentir dor e chorar. Ao término do PP, F. agradece a escuta e diz que desde que sua mãe faleceu, ele não havia conseguido chorar e que isto fez bem a ele.

Conforme afirma Safra (2004), a fragmentação do "ethos" - utilizado pelo autor como morada do homem -"leva a um tipo de sofrimento que, apesar de alcançar o registro psíquico, não tem sua origem no psíquico" (p. 26). Desta forma, no contexto da clínica contemporânea nos deparamos com questões que nos colocam como necessário o re-estabelecimento do "ethos", de forma a possibilitar o acontecer da condição humana. F. não sente ter um lugar no mundo, ao menos, para expressar seus sentimentos, vivenciar suas perdas, dores... ele pode sentir-se em sua

2 "Ethos" está sendo usado como referenciado por Figueiredo (1996), referindo-se a um conjunto de valores, posturas e hábitos considerados como uma moradia, parte do mundo no qual podemos nos sentir, relativamente, abrigados. "morada" no espaço do encontro do PP. Propiciar um espaço para tais vivências, é possibilitar que a morada - o "ethos" - seja re-estabelecida, ainda que muitos reparos e ajustes precisem ser feitos nas partes "coladas".

Além de re-estabelecer o "ethos", desempenhar funções de maternagem como o Holding ${ }^{3}$ e Continente ${ }^{4}$, em situações como a descrita acima, se faz necessário. O plantonista, como uma mãe afetuosa e maternal, a qual acolhe a angústia de morte da criança que a pede socorro por meio da linguagem do choro, funciona como um continente exitoso, devolvendo a angústia devidamente desintoxicada, com um nome e um significado.

Segundo Sapienza (2004), o paciente não vem para um encontro psicológico com questões intelectuais para resolver, mas com aquelas que se referem à sua vida e aos sentimentos que a compõem: abandono, angústia, ansiedade, medo, frustração, incerteza, tédio, desânimo, culpa, insatisfação, tristeza. Um encontro psicológico, seja este na modalidade de PP ou de psicoterapia, por ser permeado e perpassado por sentimentos humanos, é um espaço que acolhe o sentir e possibilita sua expressão - de um choro embargado, por exemplo -, sendo, além disso, um "espaço afetivo que pode servir de um novo chão, de um novo ponto de partida" (Sapienza, 2004, p. 109).

A exemplo disso, MD, 21 anos, solteiro, cursando Técnico em Administração de Empresas, procura o $\mathrm{PP}$, conforme seu relato, por ter dificuldades e medo em iniciar uma conversa, bem como mantê-la. Ele diz estar angustiado, se sentir sufocado e muito solitário, afirmando ter "muita tristeza guardada" [sic] e ser muito difícil aguentar o curso sozinho, visto que ele não conversa com ninguém de sua sala de aula. MD afirma que nunca teve uma namorada, e pergunta se é possível acreditar que "uma pessoa com 21 anos de idade que nunca tenha namorado" [sic]. Ele acredita que sua vida está, conforme seu relato, "ruim" (sem trabalho, amigos, solitário), por causa de sua timidez. Sobre sua infância e vida familiar, MD. diz que sua mãe sempre foi muito calada, parecendo-lhe uma

Termo utilizado por Winnicott, o qual alude a sustentação, tanto física como emocional, dos cuidados da mãe em relação ao bebê, ou do terapeuta em relação ao paciente (Zimerman, 2000, p. 97).

4 Similar ao Holding, mas utilizado por Bion com um significado mais amplo que este. Alude a uma função ativa da mãe que promove importantes transformações no psiquismo da criança - a mãe/terapeuta acolhe a carga das identificações projetivas (necessidades, angústias etc.) que a criança/paciente deposita dentro dela, decodificando o significado destes conteúdos, devolvendo-lhes de forma compreendida, desintoxicada, significada, transformada e nomeada, apropriada às condições da criança (Zimerman, 2000, p. 98). 
pessoa triste, e que o pai, que agredia verbalmente e fisicamente a sua mãe, sempre o tratou muito mal dizia que ele só atrapalhava, que não deveria ter nascido... Ele diz ainda que "faltou meu pai me ensinar a ser homem" [sic]. Ao ser perguntado sobre o que seria para ele ser um homem, MD diz que é ser alguém que consegue lutar pelo o que quer, não tem medo das coisas e das pessoas, e pergunta se ele conseguiria mudar. A pergunta é devolvida para MD da seguinte forma: "você acha que o ser humano é capaz de mudar?" [sic]; ele responde que sim, mas diz ter medo de não conseguir. É apontado para MD que ele já deu o primeiro passo para essa mudança, pois conseguiu vencer o medo de conversar com uma pessoa desconhecida (referindo-se à plantonista). Ele diz ser verdade e sorri. É apontado ainda para MD que ele é o autor de sua história, a qual está em construção, podendo ter as próximas páginas diferentes, caso queira. MD diz querer escrever uma história feliz, pois nunca foi feliz.

As falas de MD evidenciam o desamparo vivenciado por ele, e falhas nas funções de maternagem. Faltou alguém que o empossasse, o que nos remete a pensar na "patologia do vazio". É importante destacar que, numa visão heideggeriana, o desamparo não é, como geralmente utilizado, um mero abandono, mas uma disposição afetiva a qual tem sua raiz no ser-no-mundo como existencial abrangente do modo de ser do Dasein (Torres, 1999). Propiciar que a pessoa que vem ao encontro psicológico do PP seja "empossada" pelo plantonista, estabelecendo funções de holding e de continente para com este, é possibilitar que os buracos negros possam diminuir e a dor não ser dilacerante, mas suportável.

Assim, um encontro psicológico também é um momento de cuidado da dor e da existência da pessoa, cuidado esse que consiste em devolver a ela a obrigação do cuidado (Sapienza, 2004). Nos fragmentos do relato descrito acima, fica evidenciado um descontentamento pela vida que se tem e um desejo em mudá-la. Mudar o curso da vida não é uma tarefa simples como, usando as palavras de Sapienza (2004), perceber que tomou o ônibus errado, descer no primeiro ponto e tomar outro. Contudo, o psicólogo deve favorecer com que o paciente, ao menos, tente implementar mudanças em sua vida, ressaltando que estas são semelhantes ao processo de andar de bicicleta - que no começo pode ser difícil dar as primeiras pedaladas, que talvez se leve alguns tombos

\footnotetext{
Patologias do Vazio são aquelas nas quais a pessoa sofre de primitivas carências afetivas, e isto porque suas mais precoces necessidades vitais não foram suficientemente bem preenchidas, implicando na formação de buracos negros (Zimerman, 2000).
}

e se machuque, mas que se insistir em tentar e prosseguir, um dia se aprende a andar de bicicleta pelos parques da cidade!

É importante destacar que o encontro psicológico, além despertar no paciente o desejo, bem como a confiança, em tentar andar de bicicleta, isto é, de mudar o curso de sua vida, este pode também favorecer com que o paciente possa entrar em contato com o belo presente na vida e ao seu redor. O relato abaixo é um exemplo deste fato.

TC, 51 anos, viúva há 12 anos - seu marido faleceu por conta de um latrocínio e sua filha de 17 anos, na ocasião, após três meses da morte do pai, faleceu pelo mesmo motivo deste -, formada em Publicidade e Propaganda, reside só numa cidade que dista cerca de $50 \mathrm{~km}$ da de sua família. TC., chorando, diz sofrer de rejeição de sua mãe que tentou abortá-la ao saber da gravidez, que ela a inferiorizava, interferia na sua vida, e que a tinha internado, conforme seu relato, mesmo sem motivo e por pura implicância, por 11 vezes em hospitais psiquiátricos. TC., que tem epilepsia e faz tratamento neurológico, diz não fazer acompanhamento psiquiátrico, pois não tem depressão, mas "sentimento de rejeição" [sic]. Ela fala que precisa de colo, e colo de mãe, sendo disso que sente falta. É apontado para TC., que diz estar tudo ruim em sua volta e querer "jogar a toalha" [sic], que ela poderia ver coisas belas caso tentasse - poderia olhar para o céu e ver a bela cor azul, ver as flores dos jardins... TC., que diz gostar da natureza e de fazer meditação, enxuga suas lágrimas e deixa o encontro dizendo que olharia o belo em sua volta.

Nestes relatos, ficam evidenciados os sentimentos de abandono, rejeição, tristeza e uma significativa carência afetiva, de uma mulher que acredita que o "jogar a toalha" seja sua única saída. De acordo com Yalom (2006), os pacientes que tiverem sofrido uma longa série de perdas, eles enxergarão o mundo através dos óculos da perda. E é exatamente assim que a referida paciente vê o mundo - através das lentes da perda, da falta, do desabrigo... Poder perceber que o belo também faz parte da vida, é o que pode propiciar com que o paciente veja o mundo com uma lente, não mais em preto e branco, mas colorida.

É necessário frisar que, como afirma Yalom (2007), "um terapeuta ajuda um paciente não por analisar cuidadosamente o passado, mas por estar amorosamente presente com aquela pessoa; por ser confiável, interessado; e por acreditar que sua atividade conjunta será, fundamentalmente, redentora e curativa" (p. 242). Tais premissas não são diferentes no contexto de um PP. Estar afetivamente presente e confiável favorece com que o espaço terapêutico seja um "ethos" para a pessoa que a este recorre. 
Como oferecer hospedagem a este estrangeiro que está ali, à nossa frente, constituindo-se um enigma a ser traduzido, um mistério? O estrangeiro nos impõe os deveres da hospitalidade como evitá-lo e ou barrar sua entrada. Acreditamos que o compartilhar a constituição do mesmo espaço de encontro possibilita às pessoas se reconhecerem singulares, podendo, por isso mesmo, se expressar e constituir significados. Deparar com o estrangeiro e criar, inventar, outros modos - fora do lugar comum -, é passar pela multiplicidade de possibilidades que o mundo oferece, e, conforme Henriques (2005), o sentido é construído nesse espaço intersubjetivo aberto ao inusitado oferecido pelos encontros acontecimentais.

Parece-nos que à medida que a pessoa que sofre neste encontro do PP possa experienciar um ambiente que lhe permite "ser" (ser ela própria), ela então vai se sentindo autorizada a estar ali de forma própria. $\mathrm{Ou}$ seja, ela se constitui nas possibilidades de ser que se mostrem por meio dela mesma, pois afinal cada pessoa só pode ser aquela que ela já é. Assim, reafirmamos que o cuidado, o zelo, a atenção, a "préocupação" com aquele que rompe à nossa frente no momento do PP são condições fundamentais para o seu acontecer.

Nesse contexto, em muitas situações, cuidar, zelar, implica em ajudar a pessoa que vem ao nosso encontro no PP, ampliar seu campo de compreensão sobre o seu modo de existir, para que o cuidar de si, de sua existência, seja possível. O caso abaixo ilustra este fato.

BL, 28 anos, solteira (noiva), formada em Jornalismo e cursando Pedagogia, desempregada no momento, procura o PP dizendo que "pula de galho em galho" [sic], não para no serviço, por não saber lidar com as críticas e "enfrentar os problemas" [ $\mathrm{sic}]$ que ela acredita ser comum em qualquer ambiente de trabalho. Ela comenta que rompera com seu noivo com quem iria se casar no próximo ano, por não saber enfrentar problemas. Ao ser perguntado o que seria não saber enfrentar problemas, BL responde que não sabe ouvir críticas e que tenta fazer tudo perfeito, esperando que o outro veja o quão perfeita, legal e boa ela é. BL conta ainda que sua família parece com as que mostram nas propagandas de margarina - todos felizes e perfeitos, pessoas que se cumprimentam com abraços pela manhã; diz que seus pais a superprotegem. É apontado para BL que: "com pais tão amorosos, que fazem tudo por você, realmente você precisa se esforçar para agradá-los, para ser digna do afeto e admiração deles; então, não dá para cometer erros" [sic]. Ela concorda com a interpretação e diz ser desta forma que se sente. BL ainda completa dizendo que sua mãe a leva no seu primeiro dia num novo emprego, e que após deixá-la no local, chora muito; diz ter a sensação de ser uma criança de dois anos de idade, que tem medo de perder os pais. É apontado para BL que parece que ela está num útero quentinho e protegido, e que ao colocar o rosto para fora, isto provoca nela medo a ponto dela voltar correndo para o útero quando se sente ameaçada, revelando assim que ainda não consegue, como afirma Serres (1993), bifurcar, decidir-se por um caminho transversal que conduz a um lugar ignorado. BL ainda não sabe que experienciar só é um aprender possível se sairmos e empreendermos uma viagem.

Conforme Sapienza (2007) afirma,

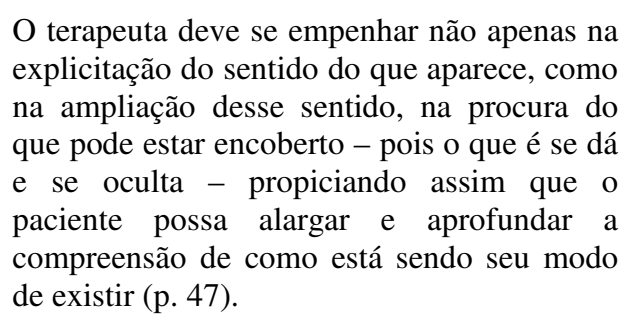

No PP, oferecer explicitação do sentido do que aparece na fala e comportamento do paciente, possibilita que a pessoa não apenas tome conhecimento deste sentido, mas que possa ampliar e compreender seu modo de ser-no-mundo.

\section{IN-CONCLUSÕES}

O presente estudo teve por intuito refletir sobre a questão do PP, desvelando que é um tipo de intervenção psicológica que busca acolher a pessoa no momento de sua urgência, fornecendo acolhimento e escuta empática.

Geralmente esta pessoa está aflita, angustiada e em sofrimento, e isso pode ser decorrente de inúmeros aspectos, tais como: as perdas que sofre; pelas escolhas que tem de tomar; dificuldades amorosas ou sentimentais; pelas angústias existenciais, enfim, são diversos fatores que levam a pessoa a procurar o PP como uma forma de saber lidar com uma situação que lhe apresenta com urgencial.

$\mathrm{Na}$ contemporaneidade, na qual vigora uma cultura do consumo, do não sentir, do não ser, na qual se defende a plenitude e um modelo de homem ideal cujo desenvolvimento chegou a seu ápice, estando este pleno e encerrado (Pompéia \& Sapienza, 2004), não é dada a devida atenção à dor, ao sofrimento e ao desespero, como se lhes fosse negado dar vazão ou lugar a tais sentimentos. É como se eles não fizessem parte da realidade de vida do ser humano.

O PP é, assim, um espaço que permite a pessoa "ser ela mesma”, que possibilita a sua expressão para desvelar seus sentimentos, as dores contidas, os choros 
embargados, sendo um espaço afetivo significativo que pode servir de um novo chão, um novo ponto de partida.

Neste ínterim compete ao psicólogo plantonista estar disponível ao que se lhe apresenta, oferecendo escuta atenta, interessada e empática, procurando o que está encoberto na fala, buscando lado a lado ao outro um modo de ser autêntico, aberto às novas possibilidades e às novas descobertas.

Para finalizar, reiteramos a importância do PP como uma intervenção psicológica diferenciada, e acima de tudo, necessária na contemporaneidade.

\section{REFERÊNCIAS}

Boff, L. (1999). Saber cuidar: ética do humano compaixão pela terra. Petrópolis (RJ): Vozes.

Calligaris, C. (2008). Cartas a um jovem terapeuta: reflexões para psicoterapeutas, aspirantes e curiosos. Rio de Janeiro: Elsevier Editora.

Cautella Júnior, W. (2009). Plantão Psicológico em hospital psicológico. In H.T.P. Morato (Org.). Aconselhamento psicológico centrado na pessoa: novos desafios (pp. 161-175). São Paulo: Casa do Psicólogo.

Chaves, P. B., \& Henriques, W. M. (2008). Plantão Psicológico: de frente com o inesperado. Psicologia Argumento, 26(53), 151-157.

Figueiredo, L.C. (1996). Revisitando as psicologias: da epistemologia à ética das práticas e discursos psicológicos. Petrópolis (RJ): Vozes.

Heidegger, M. (2001). Ser e tempo (Vol. 1). (M. S. C. Schuback, Trad.). Petrópolis (RJ): Vozes. (Obra original publicada em 1927).

Henriques, W. M. (2005). Supervisão: lugar mestiço para a aprendizagem clínica. Tese de Doutorado, Instituto de Psicologia da Universidade de São Paulo, São Paulo.

Lispector, C. (1988). A descoberta do mundo. Rio de Janeiro: Rocco.

Pompéia, J. A., \& Sapienza, B. T. (2004). Na presença do sentido: uma aproximação fenomenológica a questões existenciais básicas. São Paulo: Paulus Editora.

Safra, G. (2004). A pó-ética na clínica contemporânea. Aparecida: Idéias \& Letras.

Safra, G. (2005). A face estética do self: teoria e clínica. Aparecida: Idéias \& Letras.

Sapienza, B. T. (2004). Conversa sobre terapia. São Paulo: Educ; Paulus.

Sapienza, B. T. (2007). Do desabrigo à confiança: daseinsanalyse e terapia. São Paulo: Escuta.

Serres, M. (1993). Filosofia mestiça. Rio de Janeiro: Nova fronteira.

Tillich, P. (1976). A coragem de ser: baseado nas conferências Terry pronunciadas na Yale University. Rio de Janeiro: Paz e Terra.

Torres, J. V. (1999). Angústia e desamparo numa perspectiva heideggeriana. Revista Perspectiva Filosófica, 1(11), 145-157.

Yalom, I. D. (2006). Os desafios da terapia: reflexões para pacientes e terapeutas. Rio de Janeiro: Ediouro.

Yalom, I. D. (2007). O carrasco do amor e outras histórias sobre psicoterapia. Rio de Janeiro: Ediouro.

Zimerman, D. E. (2000). Fundamentos básicos das grupoterapias. Porto Alegre: Artes Médicas Sul.

Recebido em 10-11-2010

Aceito em 06-09-2012
Endereço para correspondência:
Andréa Marques Leão Doescher. Alameda Caetés, 117, Mirante do Vale, CEP 12302-301, Jacareí-SP, Brasil. E-mail: andreamleao@gmail.com. 